\title{
19
}

\section{The Linkage of Facts}

That all our acknowledgment of facts is a conscious submission to an Ought, is a principle which still leaves numerous aspects of our world of human experience very ill-defined. We turn to a study of some of these aspects, and of their corresponding most fundamental Categories.

Let us give at once a list of the features of our experience which are here in question. First, then, the world of Facts is a world of Likenesses and Differences. These characters we find interwoven in our world with a most baffling complexity. We endeavor to deal with them, in an elementary way, by discriminating and classifying facts. But secondly, as we proceed to classify our world, we discover, for reasons which this lecture will have to study somewhat minutely, that the acknowledged facts appear as forming Ordered Series, and so as more or less obviously grouped into Systems, and subject to Laws. These laws, which have come to characterize all our modern views of Nature, appear to us to be universal in what I have called the World of Description. A decidedly new deduction of the most fundamental categories of this World of Description will be presented in this lecture. But thirdly, the very structure of this World of Description proves, upon closer analysis, that it cannot be the final expression of the inmost nature of things. We are led, then, in a way that profoundly concerns the interests of religion, to view the true world in another light. The genuine Facts of the

[Reprinted from WI, 2:45-107.] 
universe are the facts of Life; and this, the necessary result of our general idealistic doctrine, will get a special expression in consequence of our present way of stating the contrast between the World of Description and the World of Will or of Appreciation. The one aspect of reality we shall later find embodied in the conception that nature's laws are invariable. The other aspect will receive embodiment in our Social Consciousness. The two aspects will be reconciled in subsequent lectures, by means of our Interpretation of Nature. We shall maintain that all special physical laws are only relatively invariable, and that our deepest relations to Nature are social.

To the consideration of the foregoing Categories in general, as leading up to our later study of Nature and of Man, the present lecture is to be devoted.

And first as to the Likenesses and Differences of Facts. The logic of the relations of likeness and difference first came to our notice when we were dealing with the problem of Realism in our former series of lectures. We became better acquainted with the bearing of the general concept of Being upon these relations in the course of the Ninth and Tenth lectures of that series. Here we have to deal with the topic still more at close range. Every student of these problems knows that likeness and difference are two aspects of the world that simply cannot be sundered even by the utmost efforts of abstraction. In a sense, any two objects that you recognize as real, or as possible, have points of resemblance. In a sense, also, any two objects, however nearly alike, have differences. Moreover, if you detect a difference between two objects and are asked in what respect the two differ, or are asked for what is often called the "point of difference," a moment's reflection shows you that what you name in your answer is not only a point of difference, but also a point of agreement or resemblance between the two objects. Two artists differ in style or in degree of skill. That is, they also agree in both possessing style or skill. Two solids differ in contour. That is, they both have contour, and in so far are alike. No skill of abstraction ever enables you to sunder the likenesses and the unlikenesses of facts, so as to place the two aspects of the world apart in your conception. Each depends upon the other. Where you estimate de- 
grees of likeness and difference, and call objects "more" or "less" different, you get further illustrations of the same principle. For two objects do not grow appreciably "more" different, for your usual fashion of estimate, merely by losing points of agreement. What you may often call a "very wide," or even the "widest possible" difference, comes to your consciousness in connection with contrasted or opposed objects, such as complementary colors, violent emotional changes, conflicts of will, and the like. But in such cases the difference is recognized as resting upon similarity. The complementary colors are more obviously contrasted than a color and an odor would be. Joy and grief, rage and gentleness, love and hate, are alike in being emotions, and the contrasted emotions of each pair resemble each other in being of the same more special types. Wills can differ or conflict by virtue of their relation to the same objects. On the other hand, where points of difference between objects multiply until we no longer recognize the correlative agreements, the objects in question become disparate for our consciousness. And disparity means at once the possession of so many differences that we can no longer recognize what they are, and a kind of secondary appearance of vague likenesses; since all objects whose relations we cannot clearly make out tend to lapse into a sort of blur in the background of our consciousness. There are countless differences amongst the miscellaneous objects that one sees in a crowded market-place, in case he himself is not seeking for the wares, or caring for the buyers and sellers. One observes that these differences are in one sense endless. One also observes that all this seems much alike to him; because it all means crowd and confusion, and leaves him "indifferent."

Herewith, however, we come to a point in the theory of our consciousness of likeness and difference which is, in my opinion, of critical importance for our whole doctrine about the particular facts of the world, and for our final interpretation of the problem of the individual. The likenesses and differences that we observe in facts are not merely thrust upon us without our consent or connivance. They are the objects of our attentive Interest. And they obviously vary with this interest. Nowhere more clearly than in case of our consciousness of likeness and difference do we see how significant the will is in determining what we shall regard as actual.

To attend, namely, is to take note of differences (and consequently of resemblances) which, were we inattentive, we should 
ignore. To turn our attention from certain facts, is to disregard differences of which we were before taking account. Now we are here speaking of attention, not as of a causally efficacious psychological process (for cause and effect concern us not yet), but as of one aspect of that relative fulfilment of purpose in present consciousness of which I have all along spoken. That to which we attend interests us. In attending to a sound, to a color, to an abstract conception, we find our purpose in some degree fulfilled by the ignoring or observing of some specific likenesses and differences. And the correlated likenesses and differences which appear before us in the observed facts are such as the direction of our attentive interest in some measure favors.

The world of facts is thus not merely given as like or different; it is at any moment regarded as possessing the correlative likenesses and differences to which we then and there attend. In fact, that reaction to our world, of which at the last time we spoke, is in great part an attentive attitude of the will, and is in so far a regarding of that to which we attend as more definitely different from the background of consciousness than it otherwise would be. It is perfectly true that we are not conscious of creating, i. e. of finding our purpose presently fulfilled in, more than a very subordinate aspect of the differences and correlative likenesses that we at any moment observe in the facts of our world. That is because of that relatively "foreign" character of the facts of which we spoke in defining the Ought. But it is also true that the more closely I observe, and the more carefully I submit myself to the requirement "to see the facts as they are," the more surely it is the case that the attitude of my attention in all this process of observation does, in is own degree, determine what differences amongst facts shall come to my observation. Careful measurement, for instance, that most characteristic of the processes upon which exact empirical science is based, involves a typically objective, "self-surrendering," submissive attitude of attention. Yet, on the other hand, we must insist that just this attitude, observant as it is of certain small differences which our less exact activities ignore, finds what it seeks, and what otherwise gets forced by outer nature upon nobody's observation, viz. precisely these small differences themselves, which meet our intent to be exact. What experience shows us as to the quantitative aspect of the world is, not that such differences exist wholly apart from our own or anybody's attention, but that the attentive will to measure 
does find a successful expression of its purposes in experience, so that a consciousness of small differences in lengths, times, masses, etc., comes to be recognized, where untrained and careless attention had ignored every such difference. Here, too, then, the fact observed is the fulfilment of our intent to observe that kind of fact.

In general, we may say: Likenesses and differences are not recognized by us as aspects of the world existent wholly apart from any of our specific purposes, but as correlative to certain tendencies of our will, i.e. to certain interests, which are fulfilled in recognizing these specific sorts of likenesses and differences which we come to observe. In the concrete, then, we must say, our intelligent experience involves at every step an interest in regarding facts as like or as different. This interest wins its way; and herein consists one aspect of the expression of purpose in fact which is characteristic of our own view of Being.

Most clearly this correlation of fact and purpose appears in all our Classifications. To classify is to regard certain facts as different (just because we find that to us certain differences are important), and certain objects as in a specific sense alike (because our interest in their likeness predominates over our interest in making certain possible sunderings). What classes your acknowledged world of fact contains, your own interest in classification obviously coöperates in determining. Hence the possibility of the well-known and endless disputes over whether our classifications in science stand for the truth of things, over whether our general ideas represent "external realities," and over the other historically significant problems of the theory of Universals. From our own point of view, these controversies get a very simple solution. Of course all classification is relative to the point of view, varies with that point of view, and has value only as fulfilling the purpose of whoever classifies. And, nevertheless, the question, How ought I to classify? has an objective meaning in precisely the sense in which any question about the facts of the world has meaning. Just now, when I classify mankind into two groups, you who hear me, and the rest of humanity, the classification fulfils a purpose of mine. It involves emphasizing certain presented or conceived differences, and regarding as equivalent certain facts that, from another point of view, could be subdivided or contrasted. The question whether this classification expresses anything "objective," anything bearing on the "true nature of things," is simply the question, How far is 
my momentary purpose in classifying thus an explicit and conscious expression of a certain infinitely wealthy purpose? This larger purpose comes to my present consciousness in the form of the assurance that I ought to acknowledge humanity and the universe, together with all that infinite wealth of meaning which my present thought of these objects even now hints to me,-and hints to me as that complete expression of my will which at every moment I am seeking.

The true problem about the objective validity of my classification is then the problem of the Ought, only here considered with reference to the question, What ought to be regarded as different or distinct, and what as equivalent, and in what respect? This is a teleological problem. It is to be solved, if at all, upon the ground of a consideration of the relation of this moment's passing purpose to the whole world-purpose of which it is a hint and a fragment. God distinguishes what it pleases him to distinguish. The logical as well as the moral problem is, Does my will accord with God's will?

So much, then, for Likeness, Difference, and Classification in general. The sum is so far this: Likeness and Difference are inseparable aspects of the world. Their recognition, and their very existence, are correlated with the interests which they fulfil. We express our own interests in them by means of our classifications, whose objective truth depends upon the significance of the will that makes them.

\section{II}

I pass next to an important special instance of likeness and difference, whose consideration will lead us over to the other categories of our list.

The most "subjective" of our classifications, that is, the one most expressive of the point of view of a particular consciousness, is founded on the distinction which any one of us finds himself making between the facts that he just now observes, acknowledges, thinks about, and the "rest of the universe." We not only recognize in the concrete the facts that we chance to be making the objects of our present and conscious consideration, but we all acknowledge a realm of truth beyond, whose reality we accept, but whose detail is unknown to us. London is real to us when we think of it; 
but our acknowledgment of its reality is far from being a concrete recognition of the wealth and variety of facts, social and physical, that we regard as being contained in what is meant by the name. It is so with all those distant facts which we found Realism using, at one stage of our discussion of that doctrine, as examples of independent facts that "make no difference" to a given knower, in a certain state of his knowledge. The unseen meteors of interplanetary space, the waves in the far-off seas, the craters in the moon, the ballads and legends of ancient Tartar tribes, the copper mines of Montana,-all such facts, and an infinity of others, equally varied, are lost, at any moment of our human consciousness wherein we do not concretely acknowledge their reality, in the nebulous blur of what we call "the rest of the world."

And so, what we seem to know, at any instant, consists of two regions, whose contrast is of more importance, in many ways, than is the one upon which we insisted at the opening of our former lecture. There we laid stress upon the difference between what is presented, at any instant of our consciousness, and what is then recognized or acknowledged as the expression of the theoretical Ought which controls our thinking. Here we draw the line of our classification at another place. We distinguish what either is presented or else is in some detail the object of belief, from what is acknowledged only as a whole and undifferentiated. Think of Asia, and think of some definite belief of yours regarding Asia, and what you think of is an object that, as you believe it, is indeed not now presented to your observation. But it is presented to your thought. The idea of it, as an Internal Meaning, is something of which you are definitely conscious. Yet, in addition to believing this or that about Asia, you unquestionably do recognize, however vaguely, even at the moment, that Asia is but a part of the universe whose reality you also acknowledge. Now this universe in its wholeness is real for you, at the moment, over and above Asia, because, as we have insisted, your idea of Asia is by itself unsatisfying, and so is inevitably viewed as something that cannot be expressed alone. It is felt to be essentially a fragment; and this feeling constantly tends to lead you to further thoughts, which still remain for your consciousness latent,--thoughts of the relation of Asia to the rest of the Eastern Continent, or of the relation of the Asiatic peoples to the British Empire, or to the world's history. 
But in what more concrete sense this idea of Asia needs and gets supplement through other realities, you are not conscious, so long as you fix attention upon the assertions about Asia alone.

Every concrete act of knowledge, in our conscious life, includes, then, a more or less deliberate abstraction from the background of recognized reality which we conceive as the world, for the sake of a clearer attention to certain special objects of our present acknowledgment. There results a contrast between this foreground and background of knowledge, the one containing the consciously distinguished objects of our present beliefs, the other containing only what is acknowledged in the lump, as the single and undifferentiated whole called "the rest of the universe."

Now this classification at once arouses a question as to its own basis and meaning. The question takes the form of the inquiry, What is the true relation of those various real objects of which at any moment we do not think in the concrete, to the whole state of our knowledge at that moment?

Realistic theories of knowledge, and in fact most of the popularly familiar philosophical views, even where they are only in part under the influence of technical Realism, reply to this question simply: "The objects now thought of by us are not present to our knowledge at all. They are absent objects, which do not now affect the mind. In some other state of our consciousness they may require a meaning for us. Then they become our objects. But when they are not thought of as these and these objects they are not thought of at all." This theory seems simple. It appeals to natural prejudices. But it is wholly opposed to our own analysis of the relation of Internal to External Meaning. We can entertain it no longer. It lapses with the realistic conception of Being.

For if nothing that exists exists independently of anything else, if the nature of everything is inevitably bound up with the nature of all other things, then knowledge, in facing reality at all, faces in some wise the whole of it at once, and the only question is how this at any instant takes place. The abstractness of our momentary knowledge, the vastness of our momentary ignorance of all concrete facts, no theory of knowledge recognizes more sincerely than does our own. But that all differences rest upon an underlying unity,-this is the very thesis which, in our present series of discussions, we are trying to make more concrete. For us, if you say, "The objects, other than Asia, which the world contains while I 
think, with conscious definiteness, only of Asia, must be objects of other acts of knowledge, and are in no sense present to this act," then it is necessary to reply: But the other acts of knowledge cannot, in their own Being, be wholly other than this one. For were they wholly other, they would have nothing really in common with this act. And if so, they would not be acts of knowledge at all. For two acts of knowledge have in common the real character of being knowledge. And this is a single character. If common to two facts, it gives them share in one Being. Just so, if the other objects besides Asia were wholly other than Asia itself, there would again be no community; and if Asia has Being, these other objects could have no Being. And so, in knowing Asia, I, in some sense, already know these other objects. And my knowledge, too, is in some sense one with the knowledge that more concretely possesses them. They are not, then, wholly absent objects. Even now, I, in some sense, mean them all.

Whoever denies this, after all, by implication, affirms it. For he asserts that there exist various objects, and various states of knowledge. He implies in his very assertion that his own present idea of these existences, his present meaning, is expressed in the existence of these same facts. This assertion, if true, implies a genuine unity, including, and by its nature differentiated into, the variety, not only of his sundered facts, but of these facts and his own knowledge of them.

And therefore, whoever knows any concrete object, knows in a sense all objects. In what sense is he then ignorant of any? This is for us the truly important problem.

We reply at once: The objects now concretely acknowledged are related to the objects not now concretely known, in precisely the same general sense as is that in which, at any instant of our conscious life, the objects which our attention focusses are related to what, although present, is lost in the background of consciousness. Ignorance always means inattention to details. In our momentary conscious life, such ignorance, so far as it relates to the presented contents of sense, is often due to a direction of attention which we can then and there alter by an instantaneous and voluntary shifting of our point of view. In such cases we speak of voluntary inattention, as when, in order to listen better, we neglect the facts of vision, or, in order to think better, disregard a bodily discomfort. But even within the limits of our momentary con- 
sciousness, our attention and inattention, although expressions of our will, are not always just then alterable at will. And even so, our inattention to the countless real facts, which at any moment of our human existence we altogether fail concretely to acknowledge, is due to conditions of our attention and of our inattention which we cannot at present alter except by the infinitely numerous small steps that together make up what we call the process of experience. This process of experience itself, of which empiricism justly makes much, is not, however, something determined wholly from without, by the mere coming of the facts to us. It is determined also from within, by our going to meet the facts, as we actually and restlessly do whenever we inquire, observe, or reflect. And every least shifting of our conscious momentary attention is one of these small steps whereby we continually undertake to make good the original sin, as it were, with which our form of consciousness is beset. On the other hand, this narrowness of our actual attention, this limitation to a few concrete facts, and this ignoring of the infinite detail of a world that, at any moment, we acknowledge as real only in its vague wholeness, is a condition fixed for us, not by a power wholly external to our own will, but by the very Will of which our every act of attention is the passing expression, namely, by the Will whose embodiment is the whole world of facts. And this very narrowness itself therefore constitutes, not indeed a present momentary act, but a state of our own will, a character of our present interest in the universe. This character is that we attend to only a few facts at a time, while the rest is the vague background of the world. Just as the disappointed lover of our former illustration is defeated, not without the connivance of his own will, although against his main conscious wish, so here, too, it is a present constitution of our own will that is in a genuine sense expressed in our very failure to know the detail of the universe, despite our conscious wish to know more than we do. For this inner conflict of the World Will with itself, this tragedy of satisfaction through the establishment and the overcoming of endless dissatisfaction, is a character of the universal purpose which we shall learn hereafter to appreciate, even as here we meet with an instance of it in the most elementary phenomena of the knowing process.

Our finitude means, then, an actual inattention,-a lack of successful interest, at this conscious instant, in more than a very ferw of 
the details of the universe. But the infinitely numerous other details are in no wise wholly absent from our knowledge, even now. They do "make a difference to us." Consciously we know them all at once, but know them abstractly, in the form of our acknowledgment of the "rest of the world" as real, over and above the few things we now recognize in detail. And since we are even at this instant, ourselves, in one aspect, a resultant of the meaning of all the "rest of the world," it is true, even now, that were the facts which we fail to know in detail, other than they are, our appreciation of what we do concretely know, our present attentive attitude, would be other than it is.

This is the general expression, in terms of our own theory, of the source of the present imperfections of our knowledge. Observe that we do not explain these matters by first assuming the existence of a certain being, called a finite knowing Subject, an entity amongst others, by next pointing out how knowledge gets impressed upon him from without, say through his sense-organs, and by then finally referring his ignorance to his lack of impressions. All such views, in so far as they are defensible at all, belong either to psychological theory, or, at best, to the developed metaphysical theory of the many individual Selves, and not to the general Theory of Knowledge. But Psychology, as a special science, is one result only of a particular human interest in the natural world which we shall come to know a little better in our fourth lecture. That special interest concerns us not as yet. Nor can we here presuppose that theory of the many individual Selves which we shall hereafter develope. In our general theory of finite knowledge we have to do only with the fact that a certain state of inattention exists at a certain moment of time. We know here, as yet, nothing of soul-substances, or even of metaphysical individual Subjects, such as, acted upon from without, come to build up their knowledge upon the basis of their impressions. Nor are there, from this point of view, separate series of "mental states," correlated to physical processes called brain states, and capable of being studied as to the laws of association which determine their sequence. All such conceptions can be viewed either as relatively valid, or as metaphysically final, only upon the basis to be established by a general theory of what constitutes our own type of knowledge. And for such a theory,-our whole present concern,--experience and reality alike contain only fulfilment of purpose, complete or 
incomplete, conditions of interest and attention, expressed or partially expressed in present consciousness,-acknowledgments of facts, and ignorance of facts,-beliefs, and truths related to beliefs. And of these only does the world of our considerations in this lecture consist. Hence we say, While the world in its entirety is the embodiment of our whole will, the fragment of that will, which this passing moment of human consciousness embodies, is a fragment that so far gets expressed in an attention to a few only of the world's real facts, and in such an inattention to the countless others as lets them all lapse into the vague background of acknowledged reality as "the rest of the world." Expressing the matter wholly in teleological, not at all in causal terms, we can therefore answer the question, "Why do we not now consciously and explicitly know all things, since the Being of all things is involved in our present meaning?" by saying simply, Because, as we are, we do not attend to all things, but only to a few. Or, again, Because we are not duly and sufficiently interested in the "rest of things," so that they fade into the background of knowledge, as the forests upon distant hills are lost in the contour of the rocky masses and become one with the whole. Thus simple, and in seeming no doubt paradoxical, is our formula for what is to be finite.

\section{III}

But the simplicity of the formula will prove endlessly fruitful. For this theory of our relations, as finite knowers, to the real world, predetermines what Form we ascribe to the system of facts whose reality we acknowledge.

We dealt at some length, in our study of the Third Concept of Being, with the definition of both physical and mathematical things as "objects of possible experience." But from the point of view which we have reached at the present stage of the inquiry, the facts that we acknowledge as real are for us, at any one conscious instant, Objects of Possible Attention. That is indeed not their whole Being. But it is one valid aspect of their Being. In the undifferentiated background of our present consciousness of "the rest of the world," all those real facts are even now present, but not as distinct objects. Any one of them could now be known, if only we were able to attend to its actual presence. Hence its real relationships are such as to permit, upon occasion, its discrim- 
ination from other facts in the way in which conscious attention discriminates.

Here, however, we meet, in its most elementary form, with that abstract way of viewing the world which expresses itself in the categories of the World of Description. The situation, at the moment, is this: A certain attitude of will, just now unchangeable by us, has determined each of us to a stubborn present inattention to the vast totality which we just called, in our discussion, "the rest of the world." To undertake to define the concrete facts of that world by a direct application of our general concept of Being is prevented, at the outset, by the consideration that the inattention in question hides from us not only the particular facts themselves, but the reflective knowledge of what it is that we ourselves will. For of all our human ignorance, our reflective ignorance as to the Self seems most stubborn. It is just this limitation of ours which requires us from moment to moment to view the facts in terms of the category of the Ought. We must submit in order to succeed, and must be conscious of subordinating ourselves before we can hope to find ourselves expressed. Or, to state the matter in other terms, we are in a position where we can only hope to view the world as, in the concrete, the expression of our will, in case we first can learn definitely to act; while, on the other hand, we can view our action, at the present stage, only as a reaction. We have to presuppose our facts in order to make concrete our purposes, while we can define our facts, if at all, only in terms of our purposes. This is the fatal circle of our finitude, from which we can indeed escape, as we do in some measure, at every instant, by acting,-more or less blindly,-more or less at haphazard,-seeking in the process of experience both our own purpose, and the means of executing it, both our dream, and the interpretation thereof.

But when we still try to give our undertaking the clearest definition possible at this stage, the only way is to repeat, deliberately, a process which, in a still blinder form, one sees in the early life of any being that is destined to win intelligence. Not knowing what it craves, the young creature first acts vaguely, driven by unconscious impulses. Its action is so far planless and disorganized. When trial and error have led to some few little successes, it then begins to organize its life in a more definite way-how? By watching its environment. By discriminating. By engaging in a sort of action which involves, in a sense, a temporary resignation of all 
more immediate efforts towards self-expression. This stage of growing intelligence surrenders itself to what, in us men, becomes the deliberate undertaking to describe the facts of experience as they come, and so to win indirectly a plan for what may prove to be the expression of the Self.

This effort, to be sure, is still a kind of action. It is creative as well as passive. It involves in its least movement an acknowledgment of what is not given, as well as an observation of what is given; for, as we have seen, there is no rational conception of experience except by means of a linking of present and past experience; and this act of linking is always a transcending of what is merely found. But then, this watchful, discriminating activity is seeking to attend to what is conceived as already there in the vast background of the world; and it abandons, for the time, the immediate effort to win the expression of any other purpose but the purpose to wait, and to distinguish. So (to use an example from what appears to us as the workings of a far lower form of intelligence than our own) I see, from my library window at home, sometimes, a young cat, despairing for the time of succeeding in her cherished desire to catch the gray squirrels that play about from branch to branch in the trees, and that occasionally tempt her to vain crouching and springing when they descend to the ground in pursuit of nuts. She has long hoped to find the world the expression of her Internal Meaning by getting her claws upon them. But these swift phenomena still baffle her finitude. They escape her sly approaches with à maddening agility. They scold her from above, and throw down bits of bark to insult her. At length she abandons all apparent efforts at direct attack. It becomes her will to lie for hours nearly motionless, simply watching them. She chooses, as it were, to pursue science rather than any more drastic course of action. She will learn their ways, and discriminate one of their habits from another. In her dull patience, she seems to give herself over to the study of the World of Description. It is an enlightened patience of a sort somewhat similar to this that has created for us our sciences.

Now my purpose just here is not to define the methods and the tests that are used in any special science, but to point out the most fundamental conceptions to which this way of taking the world leads us, so long as we try to abstract it from any more deliberately creative fashion of viewing things. It is plain that in 
this way we can hope for no final view of the whole truth of things. We shall be dealing with a realm of abstractions, yet they will prove to be fruitful abstractions, everywhere founded upon final truth, although in themselves not final. For, that the world permits us, up to a certain point, to describe it, does help to throw light on the true nature of things. For the rest, I shall of course attempt here no account of the psychological genesis of our describing intelligence, or of its categories. I am concerned only with the logical genesis of these ideas, that is, with the way in which their simpler forms determine their more complex ones.

We return then to the view that the real world consists of facts which are, so to speak, waiting for us to attend to their presence. What constitution must such a world possess?

In reply to this question, I must next point out certain accompaniments of the process of discrimination which are of fundamental importance for our interpretation of the structure of any realm that we are to conceive as an object of possible attention. If I discriminate attentively between two facts in space, such as two marks on a blackboard, or two sides of the same coin or die, I observe, in general, that there is something between these two discriminated objects, and also that there are regions of space between which these two distinguished objects are to be found. So that, in such a case, one discrimination demands, as it were, another. One analysis of a whole into elements calls for further analysis. And every union of discriminated elements into a new whole (as, for instance, the two sides of the die form, when taken together with the material between them, a single whole),-every such union, I say, leads us to distinguish only so much the more clearly between this new whole and the "rest of the world," which limits the observed portion so as to set it between other portions. Thus, at all events in such cases as our own consciousness of the extended world, our process of attentive discrimination tends to become a Recurrent Process, ${ }^{1}$ i.e. a process in which every step leads to conditions which demand, or at least appear to demand, a repetition of the very type of act that led to the step in question itself. For if I have discriminated, then, at least in this sort of instance, I have found a basis for a repetition of discriminations.

Now it is also plain, at least in case of such an object as the

${ }^{1}$ See the Supplementary Essay to the First Series, p. 495, sqq., for the general definition of such a process. 
world of extended things, that this very recurrent character of our process of discrimination becomes to us a motive for interpreting what we take to be the "real structure" of space itself. Because we are led, upon any clear distinction of positions in space, to an observation of an interval between two positions, while this interval itself becomes the basis for new discriminations between the positions that lie once more within that interval, we find ourselves started upon a process which we can define as recurrent, that is, as capable of repeating itself indefinitely; and since we see no reason why this process should meet with any limit in the nature of extended facts, we come to the familiar postulate of the infinite divisibility of space. And because every such observed collection of spatial objects, once discriminated, and then viewed as a whole, turns out to be between still other regions of space, which its very presence leads us to discriminate from itself, this process of discrimination also becomes recurrent, and we are led to the other familiar postulate of the boundlessness of space.

What such an instance shows is: (I) that, in certain cases at least, our tendency to discriminate two objects leads us by itself to discriminate a third object, $m$, as between them, and to distinguish other objects, let us say $f$ and $l$, between which both $a$ and $b$ are; (2) that this observation may of itself lead to new discriminations, and so become, or tend to become, recurrent; and (3) that the result hereof may be to give us an idea of an infinitely complex objective structure which we are then disposed to ascribe to a system of facts (such as the points in space). So here the law of our discriminating process gives us a conception of a law of structure in the world of facts. This law may then be to any extent confirmed by further experience.

That not only space, but also time, suggests similar recurrent processes of discrimination, is familiar.

Now these well-known instances lead us to a more general question. Is this character of the process of discrimination something general in its nature, so that, wherever we discriminate, the conditions of such recurrent processes of finding new differences are present, or is the tendency to look for points between points, and so forth, a tendency determined by special conditions, such as those of our experience of space and time? And what follows with regard to the conception that we tend to form of the structure of the world of facts? 
At first, the answer would seem to be that we may, upon occasion, come to perfectly clear limits in our discriminations. In the world of our pure conceptions, we find that between successive whole numbers, such as 2 and 3,3 and 4 , it is impossible to conceive other whole numbers inserted, so long as one takes the whole numbers in their natural order. And the same holds true, in the world of empirical things, regarding any simple series of objects whose type is that of the whole number series, where every object of the series is followed by a next one, with nothing between that belongs to the series. A series of this type we shall hereafter call, in accordance with recent mathematical usage, a Well-Ordered Series. But, on the other hand, as our Supplementary Essay showed at length, any collection of objects in the world is part of some infinite collection; and so the objects of any well-ordered series are themselves portions of the expression of a recurrent process, or of a wellordered series of such processes. And in every such process, as was shown in the Supplementary Essay, an infinite number of discriminations are already implied. Hence, although it is indeed possible to find cases where we can no longer look for objects between a given pair of objects which have already been discriminated, it still appears that discriminatons which are logically completed, merely by our distinguishing between two objects, are not to be found. Discrimination seems to be not merely of pairs, but of triads, or of larger systems of facts. ${ }^{2}$

It is then worth while to examine the matter a little more closely. For if we can find whether or no every discrimination logically leads to some such recurrent process as the empirical instance of our consciousness of space has just exemplified, we may come to a result of great importance for the formulation of the Categories in terms of which we conceive the structure of the world of facts, so far as we view them merely as objects of possible discrimination.

And may I venture already to anticipate something of what this result will prove to be? Matters of this kind are not to be studied, except by a consideration of very subtle and abstract logical rela-

2 For the sake of later use, it is proper to note here, regarding the definition of the Well-Ordered Series just given, that, while its type is that of the whole-number series, in so far forth as every term has a next following term, recent mathematical usage has extended the concept to include the so-called Transfinite Well-Ordered Series of Cantor, in which infinite series may follow infinite series without end, but so that every term has its own next following term. 
tionships. The inquiry, even in the fragmentary form here adopted, can be tolerable, in this context, only by virtue of its bearings on more concrete issues. May I, therefore, say, at once, regarding the outcome, simply this? I hold that by studying more closely what the process of discrimination logically implies, we shall be led to see something regarding what enables us to view all acknowledged facts as linked in a single Ordered System, in wbich countless definable Series of real facts are interwoven; and hereby we shall be led to a more definite idea of what is meant by the acknowledgment of Law in the natural, in the social, and in the moral order of the world. Thus our notions of the Unity of the world will become, in one aspect at least, more concrete.

How come we to the recognition of Law as an aspect of the real world? By means of some primal "intuition," which (despite its name) inflicts itself upon us as an opaque assurance? Our Idealism knows of no such primal assurances. Every assertion must bear criticism. No assertions can escape such a test by pleading that they are "primal." Or again, has the Creator, in making our souls, stamped upon them a system of principles which is in preëstablished harmony with the real order, so that our metaphysical theory, if true, will teach us that our ideas of order must correspond to an order present in the facts beyond us? With Kant we reject such a Präformations-System der Menschlichen Vernunft. Our special reason for rejecting it is contained in our thesis, so fully set forth in Lecture VII of the previous Series, to the effect that correspondence is never the most fundamental relation between Idea and Object, and that, accordingly, the world is not merely a world of facts to which our knowledge conforms. Our own view has in common with Kant (from whom we, of course, derive this portion of our fundamental doctrine) the thesis that the laws of the objective world are the expression of Categories which the nature of every subjective process, and the Unity of Apperception wherein all truth is embraced, together determine. Only, for us, the Categories are not stamped, as Kant's Categories were, upon a foreign matter, but are in some measure, i.e. as far as they are really valid at all, at once objective and subjective. This last thesis we have in common with many forms of recent Idealism. But our own doctrine is not wholly identical with any of these forms. The differentia of our doctrine will be found, however, in the method whereby we define the special Categories, and in the special form 
that we accordingly give to them. Our logical genesis of the concept of real Law will determine the definition that we shall give to the term. It will also determine the limits of the subjection of fact to law in the universe. It will free us from that bugbear of popular metaphysic, the superstition that whatever is, is somehow subject to an absolutely rigid Necessity. We shall see that necessity is only one aspect of the fact-world, and the more abstract one, which is a valid aspect only in so far as it serves to make possible Individuality and Freedom.

To my mind, as I may at once say, our best single word for expressing what is essential to a lawful order in the world of facts is the term Series. Facts are subject to law in so far as they are arranged in definable series, or in systems of interwoven serial orders. The relation of physical cause and effect, whose consideration we have so often postponed in our previous discussions, becomes a definite relation at all only when it is viewed as an instance (and by no means the most important instance) of the existence of series of facts in the universe. All comprehension of particular facts which goes beyond a bare abstract classification of them, and which still falls short of a satisfactory teleological view of their meaning, depends upon conceiving them as in the same series, or system of series, with other facts. This is the essential nature of the categories that have to do with Law. As we shall see, the general concept of Series is common to the World of Description and to the world of the actual life of the Will. Only the types of Series differ in these two worlds, the Well-Ordered Series being characteristic of the life of the Will just in so far as it is self-conscious, and consequently always knows what next to do, while the World of Description is characterized, in general, by another and less perfect type of serial order.

To illustrate empirically of what wide application the concept of Series is, and how it is present wherever the concept of Law is present, and vice versa, is useful in beginning a discussion of this category, although anything like present completeness in such illustrations is hopeless. You find serial order wherever you look in the world of definitely conceived or of exactly describable fact. Space and Time illustrate our principle in their every detail. They and the Number-Series are the most familiar of the forms in which serial order appears to us. As for more special classes of instances, I conceive my own life as a particular and connected series of 
events, and yours in the same way. All the more significant social relations involve, directly or indirectly, the establishment of serial order-systems such as those of debtors and creditors, of friends and neighbors, of fellow-citizens, of teachers and pupils, of official superiors and inferiors, of the various grades of relationships in families, and so on indefinitely. For a social relationship of the type of debtor, friend, neighbor, fellow-citizen, teacher, superior, ancestor, cousin, has the logical character illustrated by saying that if A stands in this relation to B, B may, and frequently does, stand in the same relationship to $\mathrm{C}, \mathrm{C}$ to $\mathrm{D}$, and so on,-the collection of social individuals $\mathrm{A}, \mathrm{B}, \mathrm{C}$, constituting in this way an ordered series, sometimes of a very limited, but more often of a very widely extended scope. In natural history, the classification of living forms, the study of the structures and functions of organisms, the accounts of the evolution and decay of all types of life, involve the conception of ordered series. Geology, on its descriptive side, is similarly a science of serial order-systems of rocks, fossils, formations. Nor does this character cease to mark the conceptions of science when one passes to chemistry, to physics, to astronomy, or to mechanics. The serial system of the chemical elements, which forms so important a topic of consideration in recent chemistry, is a notable example of how various masses of facts which once seemed in certain respects ultimate and mutually sundered, tend, upon further examination, to assume their places as stages of a single, though highly complex, order-system. Any natural process which is capable of a mechanical description,-such as the processes studied in the more exact regions of physical science,-is made comprehensible by conceiving all of its occurrences as stages in a single series, or system of series, of what the mathematicians call "transformations." Such a series of transformations is exemplified by the successive states of a body cooling under definable physical conditions, or by the successive configurations of a system of bodies moving under the influence of definable forces. In astronomy, the apparent places of the stars are reduced to order by the use of a system of astronomical coördinates, just as we reduce to order our knowledge of geographical positions on the earth's surface by the conceptions of latitude and longitude. But such ways of viewing facts are conceptions of definitely complex order-systems of places. In recent astronomy, moreover, the classification of the stellar spectra has led to a still tentative arrangement of stars 
in order-systems whose bearing on problems of evolution seems to be important. At all events, one thus finds a new sort of definable relation between the physical processes occurring in the very bodies that would appear, from one point of view, to be amongst the most disconnected and mutually sundered objects of the visible universe. $^{3}$

And now, as to the more universal meaning of this serial structure of our world of facts, we may note in passing still one further consideration. It is a commonplace that the exact sciences of $\mathrm{Na}$ ture have owed their exactness, up to the present time, and in the main, to their quantitative treatment of facts. The logic of the conception of Quantity has its own very complex problems; but thus much is clear: Any system of quantities, such as distances, times, masses, temperatures, pressures, is a serial order-system of facts, or is a complex of such serial order-systems. For the relationships, Equal, Greater, and Less, which mark systems of quantities, involve arrangements in serial order-systems. Therefore, one has much to say for the thesis that the whole logical value of the quantitative conceptions in science is due, not to any peculiar advantage of the concept of quantity, as such, but to the exactness of the forms of serial order which are discoverable in case of any quantitative realm of facts. From this point of view it is not, then, the quantitative character of exact science which is its most essential feature, but the precision and relative exhaustiveness of its reduction of its own ranges of fact to serial order-systems. Not Quantity, but Order, is the fundamental category of exact thought about facts. ${ }^{4}$

Now what is the logical derivation of the category of serial Order? The answer to this question requires us to return to the study of what is logically implied in coming to discriminate between any two objects. To such a study I must devote a little space, despite the painfully abstract nature of the topic. ${ }^{5}$

3 That plans of action, reflective systems of Ideas, and the structure of the Self in general, illustrate the concept of Series in the form of the WellOrdered, or self-representative Series, we have shown in the Supplementary Essay, and we shall have occasion to return to that fact soon.

${ }^{4}$ I am principally indebted for the substance of this remark to Mr. Charles Peirce, and to the study of Dedekind and Cantor. See the article on the Logic of Relatives in the Monist, Vol. VII, p. 205, sqq., by Mr. Peirce.

5 The best way of forming, from a psychological point of view, a general sense of the practical importance of the process of conceiving facts in series, 
In certain cases, as we have seen, to compare attentively two objects, as to their differences and likenesses, is to observe a situation which implies that something is between the two, and that the two themselves are again between another pair of objects. The process of discrimination and of synthesis thus initiated proves, at least in some such cases, recurrent, or self-repeating, and leads us to form postulates about the objective structure of the system of facts to which the things in question belong. In order to estimate more carefully the meaning and the universality of such processes, we next need a generalization of the relation expressed by the word between.

Such a logical generalization has been suggested, although for a purpose decidedly different from that of my present inquiry, by Mr. A. B. Kempe, in a very remarkable paper on "The Relation between the Logical Theory of Classes and the Geometrical Theory of Points."' If I venture to follow out the suggestion of Mr. Kempe's work, it is in my own way, and his discussion must not be viewed as responsible either for the intent or for the outcome of speculations. In Mr. Kempe's research, what is most important for us at the moment is that a relation of a logically identical character is shown to exist in two apparently very different cases. When three points are on the same line, one of them is said to be between the two others. But when two logical classes of objects, $a$ and $b$, are so related to a third class, $m$, that this class includes all the objects which are common to both $a$ and $b$, and at the same time is included within the class of the objects which are either $a$ or $b$, then Mr. Kempe defines the class $m$ as a class between

is to read the brilliant passages on the topic in Professor James's larger Psychology (Vol. I, p. 490; Vol. II, pp. 644-669). What Professor James there takes as a fundamental psychological feature of the process of comparison, I here try to analyze in certain of its logical aspects. The discussion in the Supplementary Essay in our First Series has already dealt in full with that primary form, the Number-Series. Here we deal mainly with a derived type of Order.

${ }^{6}$ Published in the Proceedings of the London Mathematical Society, Vol. XXI, for the year 1890 . Another statement of his main results was printed by Mr. Kempe in Nature, Vol. XLIII, pp. 156-162. These papers have been far too much neglected by the students of exact logic to whom they were addressed. Their interest goes far beyond that of the special idea which I here borrow from them. 
$a$ and $b$. The interest of the identification of the relation between in the geometrical and in the logical realms, lies in the proof, given at length by Mr. Kempe, that the exactly definable properties of any complete system of logical classes, or "Universe of Discourse," are, up to a certain limit, identical with the properties of a geometrical system of points. Mr. Kempe shows, in fact, that the system of points possible in a space of any number of dimensions differs from the system of logical classes possible in any "Universe of Discourse," merely by the addition of a single new property, viz. that which is geometrically expressed by saying that two straight lines have only one point in common. This very striking identification of laws belonging to the kinds of orderly arrangement present in such different realms as a system of ideal logical classes and a system of points in space is associated, in Mr. Kempe's discussion, with an observation regarding the nature of the generalized relation between, which I here propose to use, although I have no time to state either fully or very exactly the reasoning that I found upon this observation.

If one visible point were between two others on a line, and if all three were (to fix our ideas) luminous points, and if you went just far enough away from the line to be unable longer to observe the place of the point $a$ as diverse from that of the point $b$, so that the two blended to your eye in one luminous point, then obviously $m$, the intermediate point, would blend with both of them. Just so, however, if you abstract from the difference between the classes $a$ and $b$, while still recognizing, in a measure, the possibility of objects that, as a fact, belong to one or to another of them, then, so long as you thus regard the two classes as equivalent, it makes no conscious difference to you whether an object is in the class $a$, or the class $b$, or both at once. So that you do not observe, in that case, Mr. Kempe's intermediate class $m$ as a class different from either $a$ or $b$. The same result follows if you not merely neglect or abstract from the difference of the two classes, but positively know them to be identical classes. For in that case both $a$ and $b$ become identical with $m$.

Generalizing from these cases, one may go quite beyond Mr. Kempe's instances of the classes and the points and say, Let there be any system or collection of objects such that, if they are really different, these objects can be discriminated by an attention once properly directed. Let it be also possible for a given intelligence 
not to discriminate two objects belonging to that collection. Or again, let it be possible for this intelligence, although discriminating them, still to regard two of them at will as "equivalent," that is, as such that their difference does not count for a given purpose. Then let an object $m$ of the system in question be so related to $a$ and to $b$ that if you, either by inattention, neglect, or deliberate choice, disregard their difference, so that in any way they blend or become equivalent, $m$ thereupon of necessity blends with both, or becomes equivalent to both. In this case we shall say that, in the generalized sense, $m$ is such a member of the system in question as to lie between $a$ and $b$. The mathematical way of symbolizing this relation would be briefer. It would take the form of merely saying: " $m$ is such that, if $a=b$, then $m=a=b$. And if this is the case, $m$ is regarded as between $a$ and $b . "$

Now the advantage of this formal generalization is the power that it here gives us of facing an important logical aspect of all discrimination, comparison, and differentiation. We usually say that the relation between $a$ and $b$, where we discriminate them, or regard them as unequal, is a relation of the pair of them, a dual relation. The generalization here founded upon Mr. Kempe's paper will show us that contrast and comparison involve, in general, a relation of at least three objects, viz. $a$ and $b$, and something else that belps us to keep them apart, or that illustrates the point wherein they differ, or that helps to determine the sort, degree, or direction of their difference. This something may be an object of the exact character here ascribed to $m$. That is, it may be conceived as an object such that, if $a$ and $b$ were to blend, or were to be viewed as equivalent, it would blend with both, or be viewed as equivalent to both. In such a case, the relationship emphasized by the contrast belongs not to the pair, $a$ and $b$, but to the triad, $a, b$, and $m$. In other words, it is what one may technically name a triadic relation. The possibility of observing this relation is due to the fact that, since our discriminating attention is a voluntary act, possessed of its own internal meaning, we are able to see, by reflection, how one discrimination follows from another.

Let us look yet a little more closely at the considerations which come into view whenever we make any definite discrimination. I attend to $a$ and to $b$. I note that they are different. It follows, as we saw at the outset, that they differ in some character, and that they also, although of course in another respect, agree as to this 
same character. It may be color in which they differ. Then they agree also in having color. In magnitude,-then they agree in having magnitude. Tell me the character in which they differ, and I will at once undertake to show you the sense in which, in respect to this same character, they also agree. I inevitably note, then, if I look closer, the "common nature" of $a$ and $b$. Of course I can never, in any realistic sense, so abstract this "common nature" as to make it appear by itself as an object existing independently of their difference. Yet it is there, and arouses my interest. Otherwise I should not be comparing $a$ and $b$. They, as they come to me, appear as specifications of this "common nature."

Now when I view them as such specifications, the problem of the One and the Many arises afresh. How can this One Nature be the same in these two? This ancient question is here a question of fact. It is a question about what I actually observe when I discriminate. As it comes to me, it is already a question about a Triad, not as yet of objects, but of aspects of the whole situation before me. There is an unity here. There is also the diversity of these two objects; and this unity is not something merely glued to this diversity in an external way. The situation is this: That a certain One (viz. the "common nature" of these two objects) is observed, not as something over and above these two, but as in them,-as their nature, diversified into their differences. Yet this one is itself, nevertheless, contrasted with these two; for neither of the two, a or $b$, is by itself the other member of the pair; while the "common nature" is expressed in them both. How this can be, I so far am led to inquire. But that this is so, the discrimination implies. Here, then, I have one of those "bare external conjunctions" of the One and the Many of which Mr. Bradley, in his Appearance and Reality, has so much to say, and which, for him, constitute the insoluble problem of our finitude.

Now the effort to answer the question thus raised is not merely an idle subtlety of the philosophers. As a fact, all the sciences are full of specific contributions towards the answers to just such questions. Yes, even unreflective common sense daily undertakes to do something towards answering problems of the sort. Common sense and science, however, go about the matter more concretely than the philosophers have usually done. In ordinary life we recognize the problem of the presence of One in a pair of discriminated objects only by proceeding at once to look for still another 
instance of the same kind of likeness and difference. Baffled by the so formal triad just named, viz. the triad of the One nature and the two expressions, we help ourselves by searching out a more concrete triad. We compare, if possible, both objects with a third object, as concrete as themselves, which serves us as a "common standard." This third object is preferably an already known one, whose choice sums up the results of a long course of previous experience. To help us at all, however, it must obviously possess something of the "common nature" that interests us in $b$ and $c$. It will, of course, differ from both of them. But most of all it helps us when it is so much like $a$ and $b$, and yet so definitely unlike them, that the triad, $a, b, c$, leads us to definite observations of the sort characterized in the foregoing exact definition of the relationship between. If one of the triad is such that upon reflection we observe a particular order of dependence amongst the acts whereby we distinguish the three objects, i.e. if one object appears, as in our present sense, between the two others, then we have the first beginning of a single series of distinctions. And the rule of our discriminating intelligence is that, while the problem of the One and the Many is hopelessly baffling if we deal merely with two terms, and while it is equally hopeless so long as we deal with an indefinite number of objects not arranged in series, we begin to see the light so soon as we get one of our objects between the two others, and so begin to form a series possessing a definite character and direction. And by "direction" we here mean, not spatial or temporal direction, but direction of logical dependence.

And now why does this getting of one object between two others help us? I point out that the generalized definition of the relation between, which we owe to Mr. Kempe, suggests at once the answer to this question. I can comprehend the relation of One and Many just in so far, and only in so far, as I observe the unity of my own purpose demanding, itself of itself, a variety of expression. ${ }^{7}$ Now, when I discriminate, I at first find the fact of differ-

7 As our Supplementary Essay showed at length, the precise understanding of the relations of One and Many which we get in case of the NumberSeries, or of any "self-representative system," is due to the fact that there our own purpose in creating the system is just such a consciously self-differentiating Unity. Hence, as I there said, the order of the number-system is the original type of all order in heaven and upon earth. But we are here following out a process that leads us to a conception of order-systems very different from the number-system. For in the latter, each term has a next following 
ence as something that is indeed an expression of my attentive purpose, but that is still more an instance of the limitations of my insight. I look for light, and so far I find a problem. The object $a$ differs from $b$. How? I cannot so far tell; for I do not yet see the structure of the difference as the expression of any one plan. But when I conceive, and then am able to find in experience, some third object $c$, which behaves like the $m$ of my former definition, then, while my insight is still infinitely limited, I see the differences of $a, b$, and $c$, or, (as we may now say, in case $c$ is the intermediate object of the triad), I see the differences of $a, b$, and $m$, as such that the recognition of the difference of $b$ from $a$ follows for me inevitably upon the recognition of the difference, either of $a$ and $m$, or of $b$ and $m$, or of both. I make this fact clear to myself by trying the ideal experiment of annulling or disregarding the difference of $a$ and $m$, and of $b$ and $m$. I can try this experiment with exactness, because, in making it, I am observing my own voluntary acts. I observe hereupon that the difference between $a$ and $b$ vanishes. In convincing myself of this fact, in seeing how the distinction of $b$ from a follows from first distinguishing one of them from $m$, I gradually begin to find that the nature expressed in $a$ is such that I am led over from $a$ to $b$ by a single definable process of drawing distinctions. Or again, I thus conceive the nature of $a$ not as static and as merely given to me, but as a stage in a process that now has an actively appreciated and logically significant direction,-a direction determined by my own purposes, and also by the facts. Hereupoin I can proceed in the direction of $b$ by passing, in the course of this process, through $m$. For the very discovery of $m$, and of the dependence now in question, constitutes for me the direction of this ideal process. I now begin to construct the Many by one sort of activity. And in doing so, I also find what structure my objects themselves, as so far known to me, appear to possess.

It is perfectly true that such a process as this is far from answering all my questions about the One and the Many. On the contrary, it constantly arouses new ones. But it also suggests a systematic plan for attempting to move towards an answer to every such question. Let me find, if possible, by means of further experience,

term. In the system that we shall now be led to conceive, no term has a next term. Yet we reach these other systems by means of the first form of order, since, as we shall see, the recurrent character of our discriminations is the source of these derived order-systems. 
not only the triad, $a, m, b$, but also yet other objects similarly disposed, - a whole series of further intermediaries $\left(m_{1}\right.$ between $a$ and $m, m_{2}$ between $m$ and $b$, and so on). If I succeed in my search, I then gradually get, by means of a well-ordered series of acts of my own, a series resembling a collection of points in order on one line, thus:

$$
a \ldots m_{1} \ldots m \ldots m_{2} \ldots b .
$$

But there is room, in this series, for the conception of new intermediate terms indefinitely; and I can continue the search for such in my experience. The objects of the series are such that any three form a triad, with one of the triad between the two others (in our present sense of between), while all the triads are thus linked in one series, beginning with $a$, ending with $b$, and having intermediaries such as are determined by a recurrent process of conceiving, and, if possible, of finding in experience, ever new triads within the series. The whole series, so far as I can conceive and verify it at all, will define stages of a single process of ideal construction, which I can conceive in volitional terms, as a process that expresses bow one can pass from a to $b$, or (to borrow a mathematical term, again) can transform a into $b$. And the unity of this series, as the expression of a single volitional process, will be due to the fact that I can everywhere see, as I pass along the series, how one distinction, or act of bolding apart two objects, depends for its very existence on another and previous distinction. For in this way my ideal process, going from distinction to distinction, establishes between every pair of distinct objects, an intermediary, which is viewed by me as making their distinction possible, or as bolding them apart. Yet the intermediary terms, while they hold apart, also link.

\section{$\mathbf{V}$}

This is, then, our general statement of how it is that every discrimination tends to lead us to the definition of series of objects, observed or conceived. At the same time we begin to see how and why every such series helps us to comprehend the structure of the world that we are to acknowledge as real. Now my main thesis here is that, in the World of Description, all understanding of facts in terms of general laws depends upon the conception and 
verification of such serial order in facts as I have been characterizing. The whole logic of our conception of general law in this World of Description turns, in my view, upon the single question, What for us is implied in discriminating $a$ from $b$ ? For the world acknowledged as beyond is presented to us at every moment as a single whole, within which the facts are present. These facts are for us, in one aspect of their nature, objects of possible attention. Attention begins to succeed when we discriminate. And so we have for one postulate about the acknowledged facts this: They are such that any pair of them could be known together through a single possible act of discrimination and comparison. This is the primal notion of linkage. Any pair of real objects are thus linked. But this postulate leads to others. Whatever pair of objects there may be in that world, since both members of the pair could be the object of a single act of discriminating attention, those two objects are already like each other and different from each other. Hence the single discrimination of the two presents a new problem, that of the union of One and Many. What is the unity, what the variety of this pair? The only way that we have of proceeding towards a solution of this problem, so long as we are still ignorant in the concrete of what One Will is expressed in these objects, is by passing from the pair to the triad, and defining an object that lies between the members of the first pair, in the sense of Mr. Kempe's generalized definition of this relation. We then seek for this fact in experience. If we find it we are helped towards an understanding of the One and the Many. For in so far as we define such a triad, we discover how we could conceive one member of our original pair as transformed into the other, by means of a process that involves first distinguishing the intermediary between the two from one of the extremes, and then the other member from the object thus distinguished. The direction of the process of transformation thus defined is determined by the logical sequence, according to which one distinction is observed to follow from another. But because we are thus led better to comprehend what the objects discriminated are, we now make still a further and provisional postulate: Between any two objects of the world there is always another to be found. Our power to illustrate this postulate in our empirical investigations is very wide, but is also always limited. And the postulate itself would indeed fail wholly to receive application beyond a certain definite point, if we could 
only come to understand all the objects of our world as a single ordered series of the type of the whole number-series. For then any pair of directly successive objects would have no object between them. But, then, to be sure, the objects of the world, if so understood, would no londer need to be discriminated merely in pairs. They would be logically given, all at a stroke (like the whole numbers), as an expression of a single self-representative Purpose, ${ }^{8}$ and we should have to look no further than this purpose for the transparent definition of all our facts. But in discriminating pairs and then triads of facts, we come as yet upon no purpose, but our own descriptive purpose, of trying to find the One in the midst of this given Many. Our own process of discriminating proves indeed to be recurrent, but it looks always for yet another object between any two objects already distinguished. Hence, while the process of defining the intermediate terms is a Well-Ordered Process, that leads us from each stage to the next one, it tends to make us conceive a series of facts in which no term has any next neighbor, because, as we conceive, there is always another between. So the postulate: Between any two there is a third, is the working postulate of our process of comprehending things through our successive discriminations. And this is the process upon which all scientific description of given facts depends.

Now the definition of between suggested by Mr. Kempe's papers has quite freed us from the need of limiting the application of this postulate to the extended world, or to the numerical and quantitative aspects of things. The points on a line, as conceived by the geometer, the series of rational fractions arranged in order as greater and less, and the series of the real numbers, all indeed illustrate our postulate. ${ }^{9}$ They are conceptual systems of objects especially wrought out by the mathematician in such wise as to conform to the postulate. And every homogeneous system of measurable and continuous quantities (masses, distances, durations, forces, temperatures, etc.) is conceived by our exact science as also to illustrate this postulate. Yet the formation of series has application to qualities as well as to quantities,-in fact, to whatever we can under-

8 See once more the Supplementary Essay.

9 All these systems are so ordered that no term is conceived to have a next neighbor. Yet the process whereby we reach the conception of each is always a Well-Ordered Process, in which each of our own acts leads to the next one. 
take to discriminate. Hence there is no obvious limit to the variety of objects that we can undertake to deal with in this way. We can compare colors and shades as well as points and magnitudes. Europe and America, compared geographically, or socially, or politically, lead us to attempt the formation of series of objects. Feelings, deeds, persons, lives, stellar spectra, chemical elements, processes of evolution, types of doctrine, modes of conduct, æsthetic values, in brief, beings of all grades, invite serial treatment as soon as they are compared. Various series, already conceived, can be combined in the most varied ways, so as to give us systems of objects that no longer can be arranged in any single serial order. We thus get Systems whose series are interwoven and interrelated in most manifold fashions. Mr. Kempe's example of the classes in a single "Universe of Discourse," while it by no means exhausts the complexity of the relations that are definable through conceiving various systems of series connected together, is so complex that the space of the geometer, we have seen, corresponds to one only of the special forms definable within that system. ${ }^{10}$

The conception of systems of facts such that any two members of the system may be viewed as linked by series of intermediaries, is thus indeed capable of application in the most widely sundered regions of our experience. If we disregard the empirical limitations that we constantly meet with in our attempts to find the desired intermediary terms, and if we consider only the foregoing postulates as defining for us how we are to conceive our world of acknowledged facts, we hereupon get a view of this world which may be summed up as follows: We may omit, for the time, from our notice, the before-mentioned possibility of a knowledge of the world that would reduce it to a single serial order of the general type

$10 \mathrm{Mr}$. Kempe's system illustrates, amongst other things, very definitely the fact that the generalized conception of a series of intermediaries, linking two given objects, $a$ and $b$, is an infinitely variable concept. If two objects can be linked by one series, they can, in general, be linked by an infinity of other series of intermediaries. Thus all the classes in any Universe of Discourse are, by Mr. Kempe's definition, contained between any class $a$ and the negative of that class, not- $a$. Again between any class $a$ and a class $i$ included within $a$, you can establish an infinite number of different series of intermediate classes. It is thus also in space, if you consider the various curves by which two points can be connected. But the spatial relation of points on a line is inadequate to express all the possibilities of the generalized relation of between. In Mr. Kempe's system the same object $x$ can be defined as between $a$ and $b, b$ and $c$, and $c$ and $a$, and can yet be different from all three. 
of the Well-Ordered Series of whole numbers, where every term has one coming next after it. If we abstract from that possibility, we are left to the conception that Between any two facts there are to be found various series of intermediaries of the type now defined. The world thus regarded will consist for us of all these interwoven series, and will constitute a single System. The work of our knowledge, if we were to grow in knowledge indefinitely, on just these lines, would consist in the Description of this system. But this description would have the same general character that geometry illustrates in case of the space-world, which is only a particular example of such a linked system of interwoven series. Any such system would be capable of description in terms of Laws. The laws would express features common to various of the series present in this world. And the method of discovering laws would be, in its most general outlines, this:-

The whole system of the world may be viewed as made up of various different systems. For whole systems of facts can be discriminated from one another, and then linked by series of intermediate systems, precisely as $a$ and $b$ have been in our discussion of series in general. If, comparing two of these subordinate systems (let us say A and B), we conceive also, in some comprehensive fashion, a series of intermediary systems that link A and B together, we conceive what the mathematicians would call the "series of transformations," whereby we can, at least in our conceptions, if not in our observations, pass from one of these systems to the other. Thus, let A be, no longer, as in one of our earlier illustrations, a point in space, but a large solid body. And let B be this same body viewed by us at another time in another place, or else let it be another body of precisely the same shape and size as A, occupying another place. Let us suppose A and B compared together in one act of attention. Then we can conceive of a system of movements (consisting of translations from place to place, of rotations about one or another axis, or of a single translation followed by a single rotation),-a system whereby A could be brought to take precisely the place that B now occupies. Sometimes this serial system of movements can be actually observed. Or again, let $\mathrm{A}$ be the system of the characters, habits, and dispositions of the people of England just before the colonization of America; let B be the system of characters and habits and dispositions of the people of the North American Colonies at the middle 
of the Eighteenth Century. Then we can follow (although, in this case, only very inexactly) the series of transformations that English civilization early underwent in its passage to American soil. Other instances without limit could be named.

Between any two systems, $\mathrm{A}$ and $\mathrm{B}$, there thus lie intermediate systems of conceived, or, on occasion, of observed transformations, whereby one passes, in idea or in experience, from A to B. Now because of the general character of the relation between, as defined in the foregoing, all the intermediate transformations in any one system will be capable of being viewed as stages in a single definable process of passing from $\mathrm{A}$ to $\mathrm{B}$. This process tends to acquire the unity of a single volitional act. And this process (if we abstract from certain complications that we need not here consider) may always be viewed as having one general direction, that leads from A to $\mathrm{B}$, through the intermediary stages. But A and B will, as systems, resemble one another as well as differ. That depends upon the very nature of discrimination. And by virtue of the nature of the between relationship (just in so far as the intermediate process has one type and direction), all the intermediate stages will resemble each other in the very features in which $\mathrm{A}$ and $\mathrm{B}$ resemble each other. For all the stages between $\mathrm{A}$ and $\mathrm{B}$ are, by definition, facts that would not be viewed as different from either A or B, unless $A$ and $B$ were viewed as different each from the other. Hence all the intermediate stages must have in common the features that $\mathrm{A}$ and $\mathrm{B}$ have in common. These features then remain unvarying throughout the series of transformations in question. Denote these unvarying features (or, in the more technical way of stating the case), the "invariant characters of this system of transformations," by the letter I. Then the whole process here in question, whether it is merely conceived, or is observed, will be definable as "a series of transformations, beginning in A, ending (so far) in B, and leaving invariant the characters I."

Now all that we mean by the laws governing a system of facts is that within this system certain series of observed or of validly conceived "transformations" can be defined, such that throughout the whole series of transformations some definable characters of the objects that are undergoing the transformation do not vary. Wherever I can say that, in passing from A to B, through a series of stages which I have a right to view as real facts in the world, I observe, or validly conceive, that all the stages have certain uniform 
or "invariant" characters, I then have discovered a law which, in this way of interpreting the world, I conceive as expressing the nature and structure of the facts that I acknowledge as real.

Thus, moving a body from one part of space to another leaves, of itself, the shape of the body unchanged. Whoever discovers that, discovers the property of space defined by the so-called "axiom" or law of "free mobility." All physical and chemical changes, so far as known, leave the mass of matter unaltered. This is another example of law. All the transformations which a gravitating system of bodies undergoes are such as to leave invariant the precise system of relationships which that law defines. And so one could continue indefinitely. What laws our discriminating intelligence and our discovery of the serial linkages shall lead us to define, this view of our world leaves us unable to predict. But that some laws will come to be acknowledged, this is as certain as that the serial method of interpreting the structure of our world has, within its own limits, validity. ${ }^{11}$

\section{VI}

But what are the limits of this way of viewing things? What is the precise nature and range of its validity?

We have followed the logical genesis of the categories of what we may now call The World of Description, from their simplest forms to the point where we must abandon the attempt to develope here more fully their detail. ${ }^{12}$

The most fundamental of these categories is that of Likeness and

11 The first systematic attempt to classify the laws present in a system by regarding these laws as the "invariants" of "systems of transformations" was, so far as I know, stated in Klein's Erlanger Programm of i872: Vergleichende Betrachtungen über Neuere Geometrische Forschungen. Klein regarded the types of laws demonstrable in the various different sorts of geometry (Projective Geometry, Analysis Situs, etc.) as so many species, each definable in terms of the invariants of a Group of Transformations. The conception has since been extended to other fields of science. Owing to the irreversible character of many of the serial processes present in our experience, the "Group" character, in the narrower sense of that term, will be absent from many of the systems of transformations with which science has to deal. But a law will still be the expression of the "invariants" of a system of transformations.

12 We shall return, in our Fourth Lecture, to the consideration of these categories as they appear when applied to our actual study of nature. 
Difference. Upon the basis of a consideration of the nature of this primal conception, we come to view the Objective World as, in one aspect of its Being, a realm of Objects of Possible Attention. The Categories of Relation, which have to do with the connections existing amongst these Objects, we could not exhaustively study. Only the fundamental relation Between, in the generalized sense, attracted our closer attention, and has represented for us, in this discussion, all the Categories of Relation, although, of course, the very nature of serial order implies also the existence of countless other relations. On the basis of this conception we reached the Category of Ordered Series, although not in its only form. For the Category of Number, and of the Self-Representative System, or Well-Ordered Series, was fully discussed in our Supplementary Essay, and is here presupposed. Nor have we attempted to discuss the Category of Continuity, which would find a place in a full treatment of the Ordered Series. On the basis, however, of the Concept of Series, we indicated the nature of the more complex Category of the Ordered System, in which many series are interwoven. And thus we were led to an indication of the scope of the Category of Law as it appears in the World of Description.

So much for the mere list of concepts. Plainly these are indeed fundamental notions regarding the realm of the facts that we ought to acknowledge. But are they exhaustive? Has our world of fact no other aspect than this?

I answer at once, the world of the objects of my present possible Attention, where attention means simply the discrimination of what is already assumed to be there, is by no means the final or determinate world that the Will seeks. For, first, it is on its face a world of abstract aspects, and not of finality. It is a world of Validity, and not explicitly a world of Individuals such as our Fourth Conception demands. It is, moreover, defined in terms of a fundamental postulate that always has an altenative over against it, the alternative expressed by saying that were the world concretely viewed as a Self-Representative System, then, for one who grasped the facts in the order of that system, the recurrent process of the interpolation of intermediate terms in series already recognized would no longer express the final truth. And finally, this conception of the World of Description, although it is constantly suggested by certain aspects of experience, meets constantly its empirical limitations. We frequently make discriminations that we have to accept 
as final, without being able to comprehend them any further through discovering, in our experience, new intermediate terms. So it is when we find a limit to our power to observe finer distinctions of shades lying between two shades of gray. So it is, still more markedly, when we fail to find definite signs that between two individuals whom we believe to be real (as, for example, between two men), there are all the possible intermediate grades of individual men. Our empirical world appears to us often discrete. The problem of the "missing link" is not confined to the wellknown instances that the theory of evolution brings to our notice. And it is, above all, individuality, wherever experience suggests it to us, that seems associated with a certain discreteness.

Now it is perfectly sure that, so long as we view the world merely as the field of possible discriminations, of consequent series, and of intended abstract descriptions, we deal with all these empirical failures by noting that to discriminate two objects and yet to be unable to find an intermediary, is, so far, to be baffled as to the relation of the One and the Many. Hence, so long as we are trying merely to describe what we find, and possess no other clew, we postulate, where we do not observe, the intermediaries. Our thinking, under the influence of such postulates, moves in the direction of conceiving every discrete series as a mere fragment of a continuum. And to "understand" the world, in terms of ideal continuity, is often our provisional goal. But the deepest principle of our procedure, even in this case, is the assurance that the One and the Many can be reconciled, and that the real world is the expression of our Purpose. In conceiving the World of Description, we view the facts, however, as if the only purpose that they could fulfil was the purpose of being discriminable. But perhaps even this purpose can be reached better in some other way. Perhaps the real world forms in its wholeness a Well-Ordered Series of a discrete type. For such, as we saw in the Supplementary Essay, is the characteristic form in which Selfhood is expressed.

Let us look, however, a little more closely at the sense in which this World of Description is also a world of abstraction. Here our attention is at once attracted by a consideration that I have so far kept in the background. Our principle has so far been this, "The real world is even now virtually present to my thought at every moment, as that whole which I acknowledge. My task in trying to come to clearer consciousness about the world is to discriminate 
what it is that I acknowledge." It is indifferent, from this point of view, where I begin. Any $a$ and $b$ will do to start my investigation. Observe facts, and then look for their linkages. That is the one maxim of my procedure,-the maxim of descriptive science stated in its most abstract form. The choice of a specialty is indeed a personal matter; and because of human narrowness any one man has to confine himself to his own specialty. But all specialties have, from this point of view, their place in the endless task of describing the world. Was baben Sie neues gefunden? - this is the question which they ask of the laboratory specialist in Germany. Anytbing will do, if only it belongs to the range of one's specialty. The great world is there in the background all the time, awaiting the discriminating attention, now of this and now of that specialist. What you find must indeed be new, and, nevertheless, capable of being linked to the old. For, after all, even mere discrimination is an expression of the will, which seeks novelty. But the plan of one's discriminating procedure is indeed a self-surrendering plan. There is a heroism of sacrifice about it. I will give myself up to the facts so far as in me lies. I will find myself, only by losing myself in attentive observation of what is already there. My construction shall always be merely an acknowledgment of what I find.

But now, for such a method of work, not only any fact will do to begin with; but any point of view from which I set out will lead me to the same ideal result if only I continue this process of description. This world of facts, arranged in these abstractly conceived series, is anybody's world. All of us start from different points of view. We all, if we find this sort of truth, shall come in the end to define our results in terms of corresponding series. And this variety of possible points of view is not merely a chance accompaniment of description, but a necessary consequence of the way in which this series-forming-process of looking for what lies between any two objects proceeds. For from this point of view there is notbing about the objects, as thus discriminated, wbich makes it necessary to take them up in your investigation in one order rather than in another. Projective geometry deals with the facts of space in one way. Metrical geometry deals with them in another way. A higher development of mathematical thought shows how, by the addition of certain conceptions, one can pass from the series of conceived objects and relations of objects that projective geometry finds in space, to the series of the metrical 
geometer, and vice versa. And now there seem to be two equally justified ways of portraying the metrical properties of space. Or, in another field, in preparing the way for the description of the process of evolution, the historians and the geologists, the botanists, the zoölogists, the astronomers,-all contribute their various series of facts to be linked together in the larger generalization; and it is a mere historical accident in what order, or by what specialty, the particular series are brought to light. Hence, in general, since the discriminations upon which the formation of series depends might be made in any order, beginning with any $a$ and $b$, the World of Description is, even apart from our human social conceptions, a world where the same results are valid for various methods of approaching and so of expressing these results. It is a world, therefore, where truth is never discovered in its complete and final individual form. For the various possible ways of defining series of facts are all equally justified. But to say this is to admit that they are all equally abstract and inadequate.

When you count eggs, it "makes no difference" in what order you count them. But when you are to enjoy a Symphony, a great deal depends on the precise order in which the notes are played. When the astronomer makes a catalogue of stars, the stars appear indifferent to the order in which their positions are set down. But when you undertake to perform any rational task, such as getting through your day's duties, or serving your country, or growing in a sense of your relations to God, everything turns upon the order in which you do your work. Whatever expresses a single purpose has, as the expression of that purpose, an irreversible succession. One deed comes first, another next, and so on forever.

And now this holds true as to precisely the personal, the truly volitional aspect, of even those very processes of a descriptive sort (counting eggs, cataloguing stars, discriminating facts in their series),-such as I have here used to exemplify the apparent indifference of the serial systems of the world of description to the order in which you, or other observers, take note of their presence. The eggs and the stars appear unconcerned about the order in which you chance to take up your task of describing their serial variety. But in your life, that is, or ought to be, as orderly as the symphony or as serving God and your country, it makes a great difference to you, when you count the eggs, whether or no you count "six" after having counted "five," or skip in counting one or more of 
your well-ordered number-names. And in the life of the astronomer, considered as a man coöperating in a social task with other astronomers, the order in which the catalogue is made may be as sacred as any other moral task. Now the Reality is not the world apart from the activity of knowing beings,-it is the world of the fact and the knowledge in one organic whole.

It follows that we simply do not tell the whole story of our live relations to the world when we report the results of our formation, through successive discriminations, of series of facts. The world is unquestionably there to be known. Its facts are objects of possible attention. They can be discriminated. They do form series. But that is not the whole truth about them. The world is also there to express a perfectly determinate and absolute purpose. Its facts are incidents in a life,-yes, in a life of many lives,-a rationally connected social system of beings that embody purposes in deeds. The facts can therefore not only be discriminated, but, in so far as we ever come to be conscious of their true sense, they are linked in a teleological unity. And this unity determines not merely what is the same for many points of view, but what is uniquely present, once for all, from the divine point of view, as the one true Order of things. And the true Series is that of the Self, and of its expression in life. The true variety is that of various individual Selves, who together constitute, in their unity, the Individual of Individuals, the absolute. Beyond our own circle of concretely known facts, there are not merely series of data to be discriminated, but volitional processes to be estimated, appreciated, and conceived in their true serial order, as the stages of the world's life.

Now this conclusion is suggested, apart from our own special Theory of Being, by any fair reflection upon what happens when discriminations are made, when series of facts are found and described, when various observers, proceeding from different starting-points, reach, like the projective and the metrical geometer, or like two students of an experimental science, the same abstract results. For, as a fact, one has only to reflect in order to see, as we just saw in the case of counting the eggs, or of cataloguing the stars, that the process of discrimination, or of forming series, is itself an incident in a life whose Internal Meaning lies not merely in the acknowledgment of facts, but also in the creation of novelties. Our interest in discriminating is expressed in the joyous "I see" of the discoverer. But this is the joy of living, of creating, as well 
as finding, a world. For in merely acknowledging facts one may indeed be said to find (in the sense that I here have in mind) something that, as one conceives, another might have found as well. But one is conscious of creating, only in so far as one believes that the expression of one's purpose is an unique and individual fact, that has nowhere else in the world of Being its likeness. ${ }^{13}$ In consequence, the whole truth is that one discriminates, indeed, at every step, and in doing so acknowledges what one does not regard as one's present creation. But this very act of discrimination is, in the life of one who sees, a present, an individual, and in so far a creative expression of purpose. And the world, in permitting this expression, reveals its true essence better than the mere description of the serially arranged data reveals the final truth of things. Whoever observes merely the series of linked and discriminated facts, has therefore but to reflect in order further to observe that one's discrimination and linking of facts is itself also a fact, yet not a fact in the series discriminated,-but rather one stage in a life of self-expression. Thinking, also, is living. Science is justified as a type of action. And this is why we never can be content with discovering that the world is describable, but must note that all description is valuable as a process occurring in a life. That is why, moreover, we must always hold that the very facts themselves which we can at present interpret only in terms of Description, are the incidents of an orderly life of divine Self-Expression.

\section{VII}

All then that we said at the outset about the presence of the world in the background, as the acknowledged reality in which we are to discover all the facts that ever we are to come to acknowledge in the concrete, was, as far as it went, valid. And the conclusion that we drew as to the way in which we, from our point of view, must undertake to solve the problem of the One and the Many by the serial discrimination and linkage of facts, expresses a significant, although partial, aspect of our search for truth. But the other aspect of the truth returns of itself whenever we reflect. The world is indeed there in the background. But it is there as embodiment of

13 See the discussion of the relations between freedom, activity, and individuality in the First Series of these lectures. 
Life, and not merely as the object of discrimination. It is a world with which we stand in Social Relations. Its life coöperates with ours.

And now, as to the true serial order of this world of Life, we have, from the outset of our exposition of our Fourth Concept, recognized that, whatever the world contains, it contains in the form of a Self-Conscious Being. In our Supplementary Essay we showed at length that a Self, as a real being, has a certain form of expression, which inevitably involves a serial structure, but that this serial structure, in its main outline, is most truly represented by the form of the series of whole numbers, rather than by the form of a series between any two of whose terms, further terms without end are interpolated. A series of the latter type is indeed describable. Nor is it in the least objectionable by reason of the infinite complexity of its conceived structure. For, as the Supplementary Essay showed us, the real world is certainly infinitely complex in structure, and there is no contradiction in conceiving an infinitely complex object as real. But, from our point of view, the world of a Self, whatever continuity of internal structure it may in some aspects possess, is in its principal form of expression embodied in a discrete series of acts, of individual expressions, of stages of selfrepresentation and of self-revelation. We cannot here repeat the argument by which this result was reached in the Essay in question. But experience at any moment shows how I am conscious of my own deeds, of my progress, of my acts of attention, and of my approaches to selfhood in any way, in the form of a discrete series, in which one stage or act of life is followed by the next. The principle of my life, as I come to myself, and, knowing what I want, proceed to do it, is a principle winning novelty through Recurrence. Again and again, I proceed, from one act to the next, and so always to new acts. But neither an interpolation of deeds between my own deeds, nor yet a consciousness of unbroken continuity in my own acts, would help me to understand myself. $M y$ order, then, so far as I grasp it at all, is like the order of the numberseries, discrete. That is shown in my very process of discriminating something between any two accepted facts, so far as it is my own process. For that process, as we saw, is a recurrent one. I find that $a$ is not next to $b$, but has $m$ between. Then I conceive $m^{1}$, inserted, then $m^{2}$, and so on. But as I do this, my act of conceiving the new intermediaries comes next after a former act; and another act of 
conceiving intermediaries between $a$ and $b$ comes, in $m y$ life, next after this one.

Now if, with this fact in mind, I look back on the world which I attempted thus to describe, I find that the limitation which experience often seems to set to my postulates about the discrimination of facts, may well be founded in the deepest nature of things. The true world, the World of Values or of Appreciation, as rightly viewed by an absolute insight, would be a world of Selves, forming in the unity of their systems One Self. This world would appear to such an insight as a Social Order. For the categories of the World of Appreciation, as we shall later more fully see, when we come to the study of our human Social consciousness, are the categories of the Self in Social form and expression. But as I discriminate the world, taking account now of $a$ and now of $b$, my discrimination, determined as it is by the interest of my individual development, does not seize upon the facts in the order in which they are actually determined by the Will whose expression is the world. As I take the facts, they come to me as incidents in my individual life. Since I fail to grasp the One in the Many in these cases, I postulate the intermediaries, and have a right to do so in so far as that can further my own purpose of comprehension, which itself is a part of the world-purpose, and which is accordingly sure, within its limits, of representing one aspect of the truth. The true world, however, is not the world of description, but the world of socially interrelated Selves. And the world as we describe it, is the world viewed in the order of our own processes of description, which as incident in our human life, have their value, but are expressions of the true world order, only in so far as they reveal to us the life of things. Our conclusion is that the true series of facts in the world must be a Well-Ordered Series, in which every fact has its next-following fact. The series discoverable by us in the World of Description are characterized by the prevalence, for our view, of the relation Between. Hence they do not appear to us as Well-Ordered Series. But just in so far they are inadequate expressions of the truth.

We are now prepared to consider the more special form which these general categories will take when we come to study our human experience of Nature and of our fellows. But before we make that transition, there is still something to be said regarding one further fundamental conception,-that of Time. 